TITLE:

\title{
Metalation and Maturation of Zinc Ectoenzymes: A Perspective
}

$\operatorname{AUTHOR}(\mathrm{S})$ :

Kambe, Taiho

CITATION:

Kambe, Taiho. Metalation and Maturation of Zinc Ectoenzymes: A

Perspective. Biochemistry 2020, 59(1): 74-79

ISSUE DATE:

2020-01-14

URL:

http://hdl.handle.net/2433/245883

\section{RIGHT:}

This document is the Accepted Manuscript version of a Published Work that appeared in final form in 'Biochemistry', copyright (c) American Chemical Society after peer review and technical editing by the publisher. To access the final edited and published work see https://doi.org/10.1021/acs.biochem.9b00924.; The full-text file will be made open to the public on 13 November 2020 in accordance with publisher's 'Terms and Conditions for Self-Archiving'.; この論文は 出版社版でありません。引用の際には出版社版をご確認ご利用ください。; This is not the published version. Please cite only the published version. 


\title{
Metalation and maturation of zinc ectoenzymes: A
}

\section{perspective}

\author{
Taiho Kambe
}

Graduate School of Biostudies, Kyoto University.

\begin{abstract}
Numerous zinc ectoenzymes are folded and activated in the compartments of the early secretory pathway, such as the ER and the Golgi apparatus, before reaching their final destination. During this process, zinc must be incorporated into the active site; therefore, metalation of the nascent protein is indispensable for the expression of the active enzyme. However, to date, the molecular mechanism underlying this process has been poorly investigated. This is in sharp contrast to the physiological and pathophysiological roles of zinc ectoenzymes, which have been extensively investigated over the past decades. This manuscript concisely outlines the present understanding of zinc ectoenzyme activation through metalation by zinc and compares this with copper ectoenzyme activation in which elaborate copper metalation mechanisms are known. Moreover, based on the comparison, several hypotheses are discussed. Approximately 80 years have passed since the first zinc enzyme was identified; therefore, it is necessary to improve our
\end{abstract}


understanding of zinc ectoenzymes from a biochemical perspective, which will further our understanding of their biological roles.

\section{Introduction}

It has been approximately 80 years since carbonic anhydrase was first identified as a zinc enzyme ${ }^{l}$. Since then, significant progress has been made in understanding the physiological roles of zinc enzymes and their involvement in pathogenesis. About $10 \%$ of the human proteome is estimated to contain the zinc-binding motif ${ }^{2,3}$, with approximately one-third of cellular proteins targeted to the ER and thus to the Golgi apparatus in eukaryotic cells ${ }^{4,5}$. Therefore, a considerable number of proteins are maturated by incorporation of zinc during the secretory process before they reach their final destination. Significant parts of these proteins are zinc ectoenzymes ${ }^{6-8}$, which need the zinc ion as an essential catalytic component, and include compartment-resident, membrane-bound, and secretory enzymes, which have recently received much attention owing to their important physiological roles and their potential as therapeutic targets ${ }^{7,9-11}$. Zinc ectoenzyme representatives are alkaline phosphatases (ALPs) ${ }^{12,13}$, matrix metalloproteinases (MMPs) ${ }^{7}$, angiotensin-converting enzymes ${ }^{14}$, endothelin-converting enzymes ${ }^{15}$, ADAM (A Disintegrin and Metallo-proteinase) family proteins ${ }^{16}$, ecto-5' - nucleotidase (NT5E, also known as CD73) ${ }^{17,18}$, ectonucleotide pyrophosphatase/phosphodiesterases (ENPPs) including Autotaxin 19-21, and secretory/membrane-bound carbonic anhydrases (CAs) ${ }^{22}$, which have one or two zinc ions at their active sites (Table 1). An important question regarding zinc ectoenzymes remains, and that is how is their activation, which is achieved by zinc metalation, regulated? Here, an overview of the molecular evidence and hypothesis regarding this fundamental question is provided in a bid to understand zinc ectoenzyme regulation. 


\section{Cellular copper homeostasis and copper ectoenzyme activation}

Before discussing their zinc counterparts and to allow comparison, the activation and metalation of copper ectoenzymes are briefly overviewed, as the molecular basis of copper metalation is better understood than that of zinc ${ }^{23,24}$.

Copper taken up into the cytosol from the extracellular space, which is mediated by the copper importer CTR1 (copper transporter 1), is transferred to copper chaperone proteins, such as CCS (copper chaperone for superoxide dismutase 1 (SOD1)), COX17 (copper chaperone for cytochrome c oxidase), and ATOX1 (antioxidant-1), that deliver cytosolic copper to the target proteins $^{23,25}$ (Fig. 1). ATOX1 is pivotal for the delivery of copper to ectoenzymes as it transfers cytosolic copper to two ATPases, ATP7A and ATP7B, both of which transport it into the lumen of the trans-Golgi network ${ }^{26}$. ATP7A is ubiquitously expressed, while ATP7B is mostly expressed in hepatocytes. Both ATP7A and ATP7B are essential in supplying copper to a number of copper ectoenzymes involved in various physiological responses and pathogenesis. The representative copper ectoenzymes are lysyl oxidase (LOX) 27, 28, peptidylglycine-alpha-hydroxylating monooxygenase (PAM) 29, 30, tyrosinase ${ }^{31-33}$, dopamine beta hydroxylase (DBH) 34,35 , and extracellular superoxide dismutase (ecSOD) ${ }^{36}$. During the transfer of copper from cytosolic ATOX1 to the luminal copper ectoenzymes via ATP7A and ATP7B, a copper-mediated intermolecular interaction is formed between ATOX1 and ATP7A/ATP7B 24, 37, 38 , and between ATP7A/ATP7B and target copper ectoenzymes such as PAM ${ }^{30}$ (Fig. 2A). However, indirect (nonligand exchanged) copper transfer can be operative in the process of copper ectoenzyme metalation during direct association between them ${ }^{36,39}$. The ligand exchange through the copper-mediated 
intermolecular interaction imparts specificity to both copper and the target protein and also enables a faster exchange than a diffusion mechanism ${ }^{24}$, thus ensuring the correct and defined coordination of copper to the transporters/proteins.

\section{Cellular zinc homeostasis and zinc ectoenzyme activation}

The size of the copper proteome is generally less than $0.5 \%{ }^{40}$. In contrast, the zinc proteome is much larger and known to be about $10 \%$, as described above. The following sections overview and discuss the activation and maturation of zinc ectoenzymes by dissecting the processes described above for copper ectoenzymes: 1) zinc mobilization across the membrane by zinc transporters, and 2) metalation within the ectoenzyme.

There are 23 zinc transporter proteins that maintain subcellular, cellular, and systemic zinc homeostasis by transporting zinc across biological membranes (reviewed in ${ }^{41-44}$ ), thereby contributing to many pivotal roles in various biological processes crucial to life. Transport of zinc ions $\left(\mathrm{Zn}^{2+}\right)$ across the membranes, in contrast to copper and iron ions, does not require a redox reaction due to its fully occupied $\mathrm{d}$ shell ${ }^{45}$. In copper transporters, solute carriers (SLCs) are responsible for copper uptake (CTR1 and CTR2), while ATPases function in its export (ATP7A and ATP7B). In contrast, both the zinc transporters, ZNT and ZIP, function as SLCs. ZNT proteins operate as $\mathrm{H}^{+} / \mathrm{Zn}^{2+}$ antiporters for zinc efflux from the cytosol into the extracellular space or into the lumen of intracellular compartments ${ }^{46,47}$, while ZIP proteins transport zinc in the opposite direction, although their zinc transport mode has not been clearly determined. The $\mathrm{H}^{+} / \mathrm{Zn}^{2+}$ 
antiporter function of ZNT proteins is useful for zinc transport into the acidic environment of the lumen of intracellular compartments ${ }^{48,49}$.

Zinc taken up into the cytosol by ZIP proteins must be transferred to the lumen of the compartments of the early secretory pathway, such as the ER and Golgi apparatus, for zinc ectoenzyme activation. Therefore, a specific zinc entry route is required to cross biological membranes (Fig. 3). In vertebrate cells, two routes are present, consisting of ZNT5-ZNT6 heterodimers and ZNT7 homodimers. At present, the fundamental question of how cytosolic zinc is derivered to both ZNT complexes has not yet been answered. In copper metabolism, ATOX1 plays a pivotal role in cytosolic copper delivery to copper-transporting ATPases located in the trans-Golgi network, as described above. This kind of chaperone protein might operate for zinc delivery, because such a chaperone would enable specific and timely zinc delivery to ZNT complexes, as in the case of ATOX1. From this perspective, zinc may be transferred via ligand exchange through zinc-mediated protein-protein interactions without the release of zinc ${ }^{50,51}$ (Fig. 2B and C). Actually, zinc-mediated intermolecular interactions are formed within a number of protein complexes in cells ${ }^{52-54}$.

Addition of excess zinc to the spent medium fails to activate the apo-forms of zinc ectoenzymes secreted from cells cultured under zinc-deficient conditions ${ }^{55}$, indicating that zinc metalation in the compartments of the early secretory pathway is essential for zinc ectoenzyme activity. In the cell, cytosolic zinc is transported across the membrane to the lumen of these compartments by ZNT5-ZNT6 heterodimers and ZNT7 homodimers ${ }^{56-58}$ (Fig. 3). Therefore, both ZNT transport complexes are pivotal for metalation and activation of zinc ectoenzymes ${ }^{55,59-61}$, although the direct comparison of the zinc content of zinc ectoenzymes biosynthesized in wildtype cells with that in the cells lacking both complexes has not been made. However, some insight 
into this process is available. In cells lacking both ZNT complexes, the activities of TNAP, placental ALP (PLAP), NT5E, Autotaxin, and MMP9 decrease dramatically, as is the case in cells expressing the ectoenzymes under zinc-deficient conditions ${ }^{55,59-61}$. However, there are significant differences between the two cases; ectoenzymes, except for Autotaxin, expressed in the former case are destabilized and degraded, but this does not occur in the latter (Table 1) ${ }^{55,59-61}$. In contrast, CAIX, ENPP1 and ENPP3 retain their activity even when expressed in cells lacking both ZNT complexes (Table 1) ${ }^{55,61}$. However, CAIX activity moderately decreases when ZNT4 homodimers are also absent (Table 1) ${ }^{61}$. ZNT4 is shown to be involved in the abundance of CAVI ${ }^{62}$, suggesting its roles in the activation process in some zinc ectoenzymes. The differences in the dependence of ZNT proteins on the activation are not attributed to the number of zinc ions at their active sites (Table 1), suggesting that a sophisticated mechanism underlies zinc-mediated activation of zinc ectoenzymes.

Exactly how and when do zinc ectoenzymes acquire zinc at their active sites in the lumen of the compartments of the early secretory pathway? As described above, a number of zinc ectoenzymes are destabilized when expressed in cells lacking ZNT5-ZNT6 heterodimers and ZNT7 homodimers, which was restored by the expression of either complex, and also by the expression of their zinc transport incompetent mutants, suggesting that both ZNT complexes can stabilize several zinc ectoenzymes, in addition to their primary functions in zinc metalation. TNAP is rapidly degraded as an endo-H-sensitive form through ubiquitin-proteasomal and lysosomal

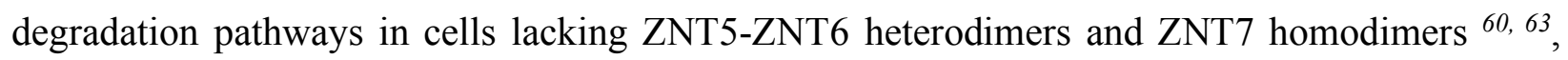
which indicates that the TNAP activation process by ZNT complexes may be separated into two steps, the first being a stabilization step and the second a zinc-metalation step (Fig. 4). The molecular mechanism underlying this process remains almost entirely unknown; however, the 
highly conserved Pro-Pro motif in luminal loop 2 between transmembrane helices III and IV of ZNT5 and ZNT7 (as ZNT5 has nine extra N-terminal transmembrane helices, the luminal loop 2 actually corresponds to its luminal loop $6^{64}$ ) may be involved. This motif is not found in other ZNT proteins, which failed to activate TNAP even when overexpressed ${ }^{65}$, and mutants of ZNT5 and ZNT7 in which Pro-Pro is substituted with Ala-Ala exhibit significantly decreased ability to activate TNAP, despite retaining their zinc transport activity ${ }^{65}$. Thus, a unique structural feature of the Pro-Pro motif may contribute to the activation of TNAP, potentially via a unique interaction. Interestingly, the situation is somewhat different in Autotaxin. Autotaxin is not degraded in cells lacking ZNT5-ZNT6 heterodimers and ZNT7 homodimers, although it is not active ${ }^{61}$. The ProPro motif ZNT5 mutant moderately activates Autotaxin, which may suggest that motifs other than the Pro-Pro motif in ZNT5-ZNT6 heterodimer are involved in Autotaxin activation ${ }^{61}$. The stabilization of Autotaxin may be reminiscent of copper ectoenzymes such as PAM, ecSOD, and $\mathrm{DBH}^{30,36,39}$, which are associated with ATP7A as described above. If applying the metalation mechanism of PAM by ATP7A ${ }^{30}$, a challenging but attractive hypothesis is that zinc-mediated intermolecular interactions ${ }^{50,51}$ are formed between ZNT complexes and Autotaxin (Fig. 2B). Further investigation is required to determine this.

The absence of ZNT complexes exacerbates the unfolded protein response ${ }^{63}$, thus disturbing the quality control mechanisms of the early secretory pathway such as the ER. This unfolded protein response could be due to an increase in misfolded apo-zinc ectoenzyme, or a decrease in the chaperone activity, which is essential for facilitating zinc metalation of nascent zinc ectoenzymes, as a number of chaperones function in the quality control of the ER and the secretory pathway, some of which are regulated by zinc ${ }^{66,67}$. Consistent with these, zinc deficiency exacerbates unfolded protein response ${ }^{63,68}$. 


\section{Conclusions and perspectives}

Numerous genetic and biochemical studies have elucidated the physiopathological significance of zinc ectoenzymes $11,42,43,69,70$. However, as described, numerous questions remain. One reason for this is that it is difficult to investigate zinc coordination using UV-visible absorption, nuclear magnetic resonance, or electron paramagnetic resonance spectroscopies, because of the filled $\mathrm{d}$ shell of the zinc ion. The development of zinc fluorescent probes and fluorescence resonance energy transfer sensors has contributed significantly to our understanding of zinc ${ }^{71-73}$; however, a new innovative approach needs to be developed and exploited to provide a new direction for zinc research. For zinc ectoenzyme activation, a detailed 'zinc-ome' analysis, which can distinguish between the apo- (not metalated) and holo-form (metalated) of zinc ectoenzymes, coupled with a genetic approach may significantly advance our understanding. This may potentially lead to the development of new therapeutic strategies, considering their association with physiopathology. 
Table 1. Activation and stability of zinc ectoenzymes when expressed in cells lacking ZNT5-ZNT6 heterodimers and ZNT7 homodimers.

\begin{tabular}{|c|c|c|c|c|}
\hline Ectoenzymes & $\begin{array}{l}\text { Metalated zinc } \\
\text { ions }\end{array}$ & Enzyme activity & Protein stability & Reference \\
\hline TNAP & 2 & Inactive & unstable & $57,59,60,65,74$ \\
\hline NT5E & 2 & Inactive & unstable & 55 \\
\hline Autotaxin & 2 & Inactive & stable & 61 \\
\hline MMP9 & 1 & Inactive & unstable & 61 \\
\hline PLAP & 2 & Inactive & unstable & 55,59 \\
\hline ENPP1* & 2 & Active & stable & 55 \\
\hline ENPP3* & 2 & Active & stable & 55 \\
\hline CAIX $^{* *}$ & 1 & Active & stable & 61 \\
\hline CAVI*** & 1 & N.A. & N.A & 62 \\
\hline
\end{tabular}

*The activity and protein expression do not decrease even when expressed in cells lacking all ZNT4 homodimers, ZNT5-ZNT6 heterodimers, and ZNT7 homodimers. **The activity and protein expression moderately decrease in cells lacking all ZNT4 homodimers, ZNT5-ZNT6 heterodimers, and ZNT7 homodimers. ***The activity moderately decreases in cells with reduced ZNT4 expression. 


\section{FIGURE LEGENDS}

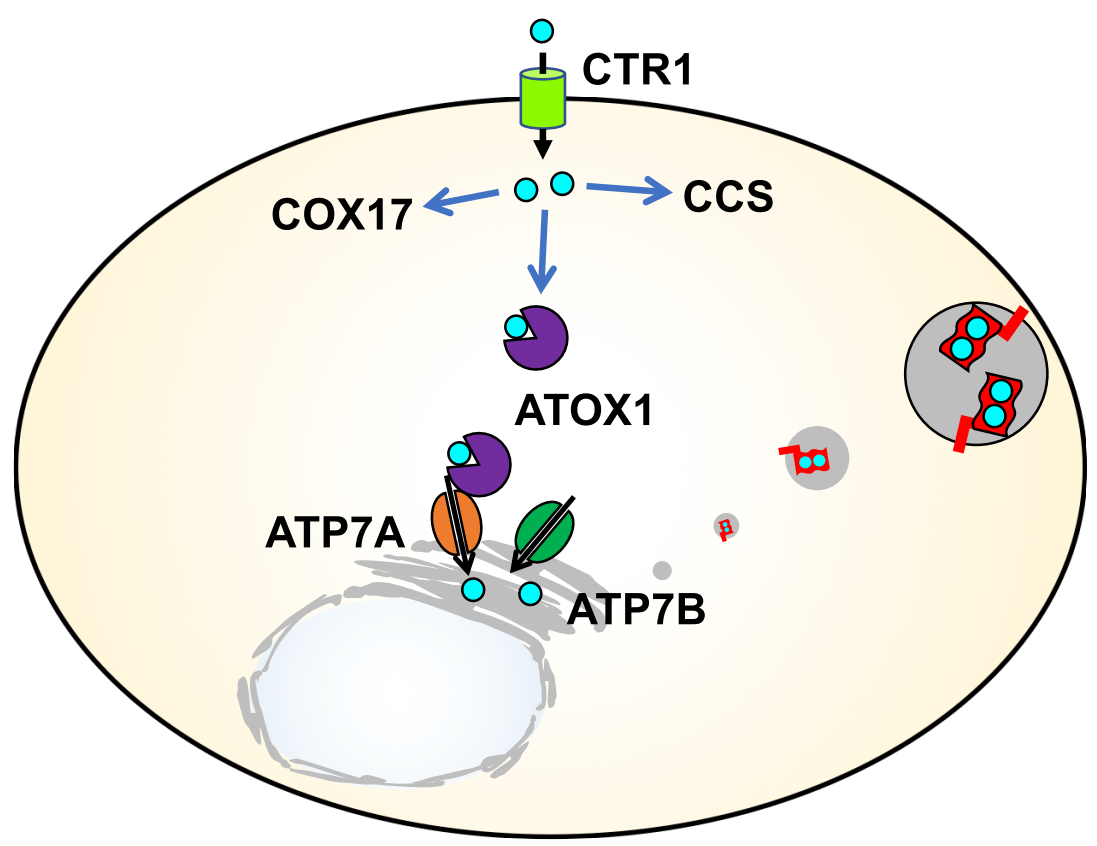

Figure 1. Simple model of cellular copper metabolism for copper ectoenzyme metalation and activation

Copper is taken up into the cytosol by CTR1 and then distributed to three cytosolic copper chaperones, COX17, CCS, and ATOX1. COX17 delivers copper to the mitochondrial inner membrane, and CCS delivers it to cytosolic SOD1 (not shown). ATOX1 delivers cytosolic copper to ATP7A and ATP7B, located in the trans-Golgi network, which then transports it to the lumen of the trans-Golgi network to metalate and activate copper ectoenzymes. In this cartoon, the holoform of the copper ectoenzyme is trafficked and localized to the intracellular compartments as a monomer. $\mathrm{Cu}^{+}$is represented by a light blue sphere. 
(A)

\section{Copper-mediated protein-protein interaction}

Donor
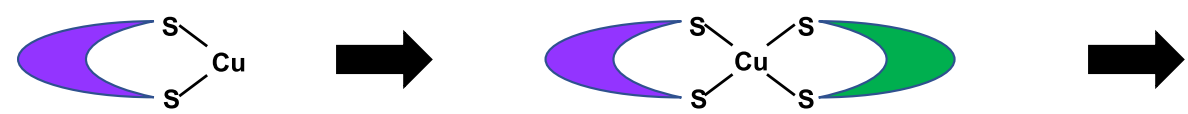

Acceptor

(B)

\section{Zinc-mediated protein-protein interaction}
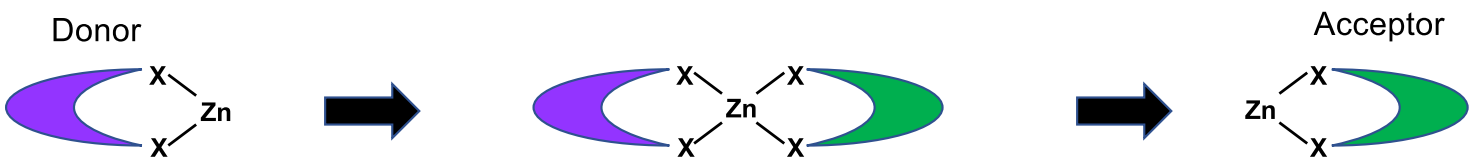

(C)

\section{Freely released zinc ion}
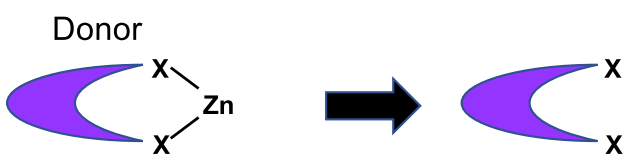

$\mathrm{Zn}$

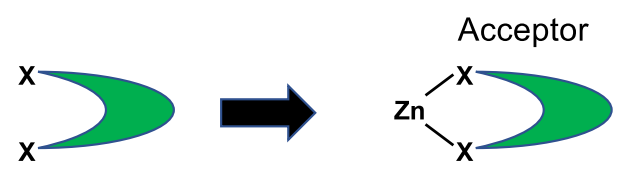

Figure 2. Model of copper transfer and hypothesis of zinc transfer from the donor to the acceptor proteins

(A). The ligand exchange mechanism in copper transfer. An intermolecular interaction via the copper ion $\left(\mathrm{Cu}^{+}\right)$is formed during delivery. The combination of donor and acceptor proteins corresponds to that of ATOX1 and ATP7A/ATP7B, or that of ATP7A/ ATP7B and the copper ectoenzyme. Sulfur from the sulfhydryl group of cysteine is functional as a ligand for the copper ion in donor and acceptor proteins. (B). A hypothesis of the ligand exchange mechanism in zinc transfer. An intermolecular interaction via the zinc ion is formed between donor and acceptor proteins during delivery as in the case of copper. (C). Non-ligand-mediated zinc transfer. The zinc ion $\left(\mathrm{Zn}^{2+}\right)$ is freely released from the donor protein for delivery to the acceptor protein, in which an intermolecular interaction is not formed. In (B) and (C), X usually corresponds to sulfur from the sulfhydryl group of cysteine and nitrogen from the imidazole ring of histidine. 


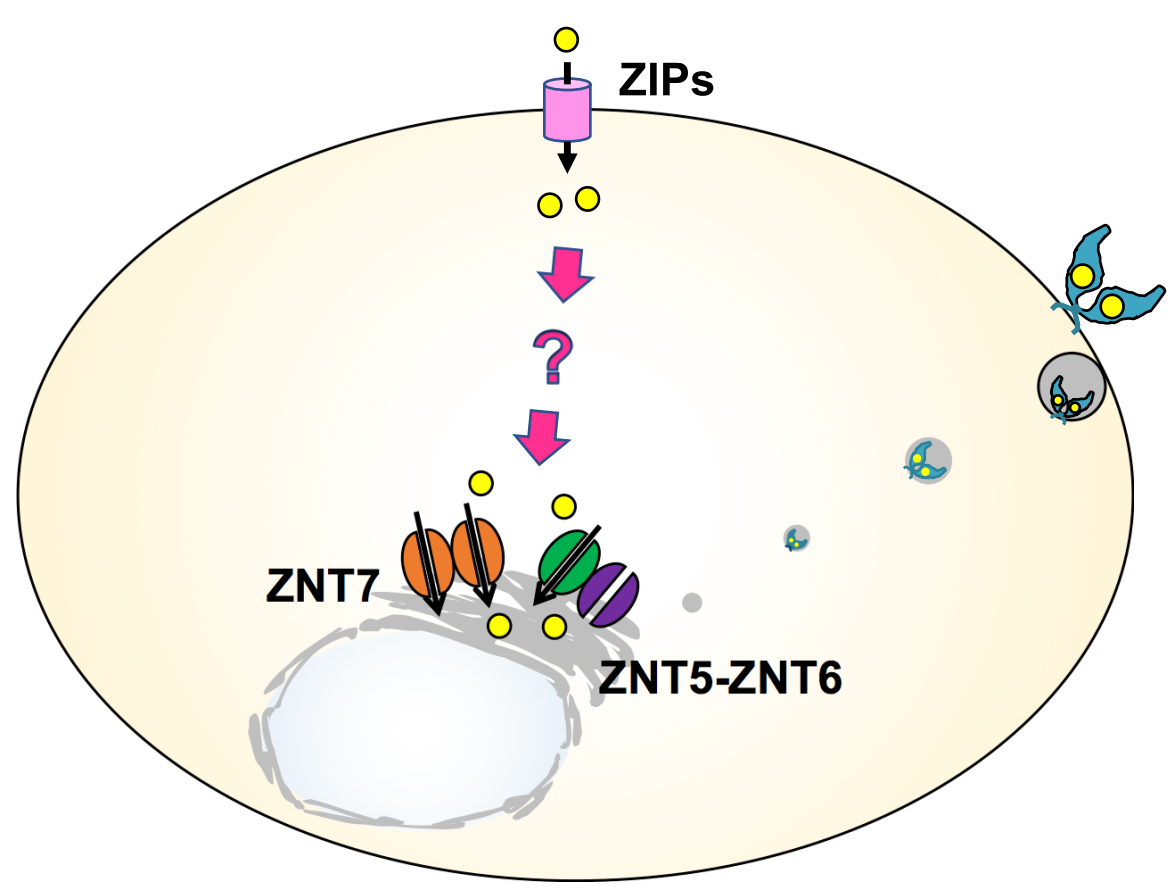

Figure 3. Simple model of cellular zinc metabolism for zinc ectoenzyme metalation and activation

Zinc is taken up by ZIP transporter proteins into the cytosol and then derivered to ZNT5ZNT6 heterodimers and ZNT7 homodimers, both of which are located close to the compartments of the early secretory pathway, such as the ER and Golgi apparatus. Both ZNT complexes transport cytosolic zinc to the lumen of these compartments to metalate and activate zinc ectoenzymes. In ZNT5-ZNT6 heterodimers, ZNT6 does not possess zinc transport activity. Zinc transport activity is depicted by an arrow. Information regarding the molecular mechanism by which cytosolic zinc is derivered to both ZNT complexes is lacking. In this cartoon, the holo-form of a zinc ectoenzyme is trafficked and localized to the plasma membrane as a homodimer. $\mathrm{Zn}^{2+}$ is represented by a yellow sphere. 

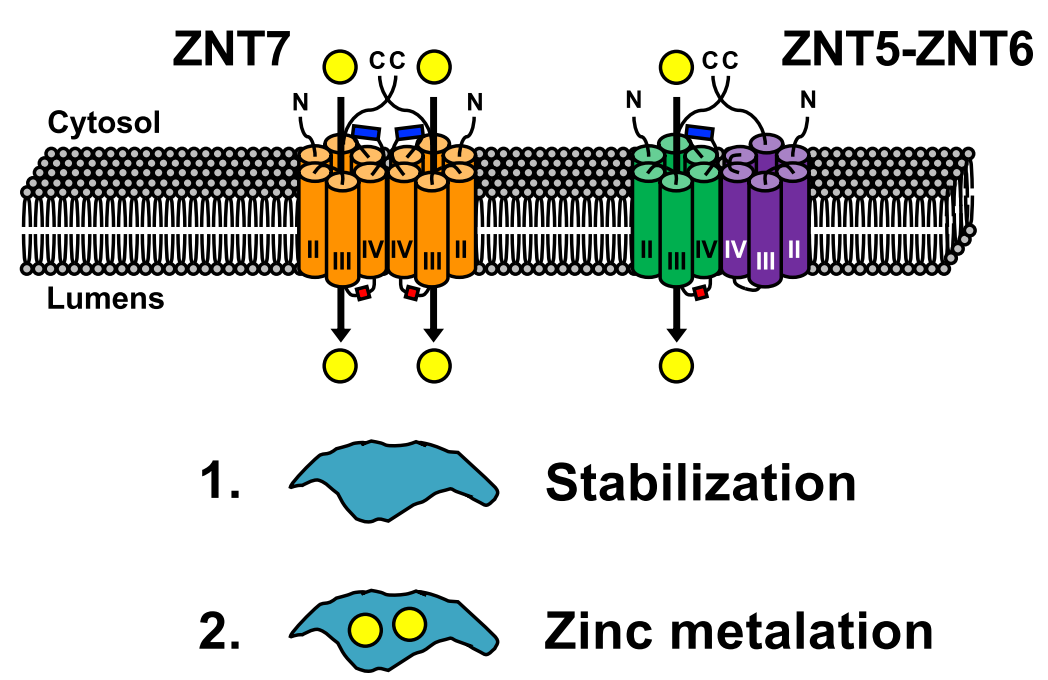

Figure 4. ZNT complexes contribute to both stabilization and metalation of zinc ectoenzymes in the compartments of the early secretory pathway

ZNT5-ZNT6 heterodimers and ZNT7 homodimers activate zinc ectoenzymes via two steps in the compartments of the early secretory pathway; first, stabilizing the ectoenzymes apoform, and second, zinc metalation by transporting cytosolic zinc to the lumen, converting the enzyme to its holo-form. The Pro-Pro motif in luminal loop 2 between transmembrane helices III and IV is shown as a red square. The cytosolic histidine-rich loop is shown in blue square to discriminate the position of the Pro-Pro motif from it. The detailed molecular mechanism of this process remains unknown. Luminal loop 2 of ZNT5 actually corresponds to luminal loop 6, because of its long N-terminal portion with nine extra transmembrane helices (not shown). $\mathrm{Zn}^{2+}$ is represented by a yellow sphere. 


\section{AUTHOR INFORMATION}

\section{Corresponding Author}

* Taiho Kambe

Graduate School of Biostudies

Kyoto University, Kyoto 606-8502, Japan

E-mail: kambe1@kais.kyoto-u.ac.jp

Tel: $+81-75-753-6273$

\section{Funding Sources}

This work was supported by a Grant-in-Aid for Scientific Research on Innovative Areas "Bio-metal" (KAKENHI, 19H05768) from the Ministry of Education, Culture, Sports, Science, and Technology, Japan.

\section{Notes}

The authors declare no competing financial interest.

\footnotetext{
Abbreviations

SLCs, solute carriers; ALPs, alkaline phosphatases; MMPs, matrix metalloproteinases; NT5E, ecto-5'-nucleotidase; ENPPs, ectonucleotide pyrophosphatase/phosphodiesterases; CAs, carbonic anhydrases; TNAP, tissue non-specific ALP; PLAP, placental ALP; CTR1, copper
} 
transporter 1; SOD1; superoxide dismutase 1; CCS, copper chaperone for SOD1; COX17, copper chaperone for cytochrome c oxidase; ATOX1, antioxidant-1; ecSOD, extracellular superoxide dismutase; LOX, lysyl oxidase; PAM, peptidylglycine-alpha-hydroxylating monooxygenase.

\section{REFERENCES}

[1] Keilin, D., and Mann, T. (1939) Carbonic Anhydrase, Nature 144, 442-443.

[2] Andreini, C., Banci, L., Bertini, I., and Rosato, A. (2006) Counting the zinc-proteins encoded in the human genome, $J$ Proteome Res 5, 196-201.

[3] Andreini, C., Bertini, I., and Cavallaro, G. (2011) Minimal functional sites allow a classification of zinc sites in proteins, PLoS One 6, e26325.

[4] Vembar, S. S., and Brodsky, J. L. (2008) One step at a time: endoplasmic reticulumassociated degradation, Nat Rev Mol Cell Biol 9, 944-957.

[5] Dejeans, N., Manie, S., Hetz, C., Bard, F., Hupp, T., Agostinis, P., Samali, A., and Chevet, E. (2014) Addicted to secrete - novel concepts and targets in cancer therapy, Trends Mol Med 20, 242-250.

[6] Kambe, T., Takeda, T. A., and Nishito, Y. (2016) Activation of zinc-requiring ectoenzymes by ZnT transporters during the secretory process: Biochemical and molecular aspects, Arch Biochem Biophys 611, 37-42.

[7] Overall, C. M., and Lopez-Otin, C. (2002) Strategies for MMP inhibition in cancer: innovations for the post-trial era, Nat Rev Cancer 2, 657-672.

[8] Hausmann, J., Perrakis, A., and Moolenaar, W. H. (2013) Structure-function relationships of autotaxin, a secreted lysophospholipase D, Adv Biol Regul 53, 112-117.

[9] Winum, J. Y., Scozzafava, A., Montero, J. L., and Supuran, C. T. (2006) Therapeutic potential of sulfamides as enzyme inhibitors, Med Res Rev 26, 767-792.

[10] Supuran, C. T. (2008) Carbonic anhydrases: novel therapeutic applications for inhibitors and activators, Nat Rev Drug Discov 7, 168-181.

[11] Egeblad, M., and Werb, Z. (2002) New functions for the matrix metalloproteinases in cancer progression, Nat Rev Cancer 2, 161-174.

[12] Millan, J. L., and Fishman, W. H. (1995) Biology of human alkaline phosphatases with special reference to cancer, Crit Rev Clin Lab Sci 32, 1-39.

[13] Mornet, E., Stura, E., Lia-Baldini, A. S., Stigbrand, T., Menez, A., and Le Du, M. H. (2001) Structural evidence for a functional role of human tissue nonspecific alkaline phosphatase in bone mineralization, J Biol Chem 276,31171-31178.

[14] Natesh, R., Schwager, S. L., Sturrock, E. D., and Acharya, K. R. (2003) Crystal structure of the human angiotensin-converting enzyme-lisinopril complex, Nature 421, 551-554.

[15] Turner, A. J., and Tanzawa, K. (1997) Mammalian membrane metallopeptidases: NEP, ECE, KELL, and PEX, Faseb J 11, 355-364.

[16] Seals, D. F., and Courtneidge, S. A. (2003) The ADAMs family of metalloproteases: multidomain proteins with multiple functions, Genes Dev 17, 7-30. 
[17] Knapp, K., Zebisch, M., Pippel, J., El-Tayeb, A., Muller, C. E., and Strater, N. (2012) Crystal structure of the human ecto-5'-nucleotidase (CD73): insights into the regulation of purinergic signaling, Structure 20, 2161-2173.

[18] Garavaglia, S., Bruzzone, S., Cassani, C., Canella, L., Allegrone, G., Sturla, L., Mannino, E., Millo, E., De Flora, A., and Rizzi, M. (2012) The high-resolution crystal structure of periplasmic Haemophilus influenzae NAD nucleotidase reveals a novel enzymatic function of human CD73 related to NAD metabolism, Biochem J 441, 131-141.

[19] Kato, K., Nishimasu, H., Okudaira, S., Mihara, E., Ishitani, R., Takagi, J., Aoki, J., and Nureki, O. (2012) Crystal structure of Enpp1, an extracellular glycoprotein involved in bone mineralization and insulin signaling, Proc Natl Acad Sci U S A 109, 16876-16881.

[20] Nishimasu, H., Okudaira, S., Hama, K., Mihara, E., Dohmae, N., Inoue, A., Ishitani, R., Takagi, J., Aoki, J., and Nureki, O. (2011) Crystal structure of autotaxin and insight into GPCR activation by lipid mediators, Nat Struct Mol Biol 18, 205-212.

[21] Hausmann, J., Kamtekar, S., Christodoulou, E., Day, J. E., Wu, T., Fulkerson, Z., Albers, H. M., van Meeteren, L. A., Houben, A. J., van Zeijl, L., Jansen, S., Andries, M., Hall, T., Pegg, L. E., Benson, T. E., Kasiem, M., Harlos, K., Kooi, C. W., Smyth, S. S., Ovaa, H., Bollen, M., Morris, A. J., Moolenaar, W. H., and Perrakis, A. (2011) Structural basis of substrate discrimination and integrin binding by autotaxin, Nat Struct Mol Biol 18, 198204.

[22] Purkerson, J. M., and Schwartz, G. J. (2007) The role of carbonic anhydrases in renal physiology, Kidney Int 71, 103-115.

[23] Lutsenko, S., Barnes, N. L., Bartee, M. Y., and Dmitriev, O. Y. (2007) Function and regulation of human copper-transporting ATPases, Physiol Rev 87, 1011-1046.

[24] Robinson, N. J., and Winge, D. R. (2010) Copper metallochaperones, Annu Rev Biochem 79, 537-562.

[25] Kim, B. E., Nevitt, T., and Thiele, D. J. (2008) Mechanisms for copper acquisition, distribution and regulation, Nat Chem Biol 4, 176-185.

[26] La Fontaine, S., Ackland, M. L., and Mercer, J. F. (2010) Mammalian copper-transporting P-type ATPases, ATP7A and ATP7B: emerging roles, Int J Biochem Cell Biol 42, 206209.

[27] Finney, J., Moon, H. J., Ronnebaum, T., Lantz, M., and Mure, M. (2014) Human copperdependent amine oxidases, Arch Biochem Biophys 546, 19-32.

[28] Shanbhag, V., Jasmer-McDonald, K., Zhu, S., Martin, A. L., Gudekar, N., Khan, A., Ladomersky, E., Singh, K., Weisman, G. A., and Petris, M. J. (2019) ATP7A delivers copper to the lysyl oxidase family of enzymes and promotes tumorigenesis and metastasis, Proc Natl Acad Sci U S A 116, 6836-6841.

[29] Steveson, T. C., Ciccotosto, G. D., Ma, X. M., Mueller, G. P., Mains, R. E., and Eipper, B. A. (2003) Menkes protein contributes to the function of peptidylglycine alpha-amidating monooxygenase, Endocrinology 144, 188-200.

[30] Otoikhian, A., Barry, A. N., Mayfield, M., Nilges, M., Huang, Y., Lutsenko, S., and Blackburn, N. J. (2012) Lumenal loop M672-P707 of the Menkes protein (ATP7A) transfers copper to peptidylglycine monooxygenase, J Am Chem Soc 134, 10458-10468.

[31] Solano, F. (2018) On the Metal Cofactor in the Tyrosinase Family, Int J Mol Sci 19.

[32] Petris, M. J., Strausak, D., and Mercer, J. F. (2000) The Menkes copper transporter is required for the activation of tyrosinase, Hum Mol Genet 9, 2845-2851.

[33] Setty, S. R., Tenza, D., Sviderskaya, E. V., Bennett, D. C., Raposo, G., and Marks, M. S. 
(2008) Cell-specific ATP7A transport sustains copper-dependent tyrosinase activity in melanosomes, Nature 454, 1142-1146.

[34] Vendelboe, T. V., Harris, P., Zhao, Y., Walter, T. S., Harlos, K., El Omari, K., and Christensen, H. E. (2016) The crystal structure of human dopamine beta-hydroxylase at 2.9 A resolution, $S c i$ Adv 2, e1500980.

[35] Xiao, T., Ackerman, C. M., Carroll, E. C., Jia, S., Hoagland, A., Chan, J., Thai, B., Liu, C. S., Isacoff, E. Y., and Chang, C. J. (2018) Copper regulates rest-activity cycles through the locus coeruleus-norepinephrine system, Nat Chem Biol 14, 655-663.

[36] Qin, Z., Itoh, S., Jeney, V., Ushio-Fukai, M., and Fukai, T. (2006) Essential role for the Menkes ATPase in activation of extracellular superoxide dismutase: implication for vascular oxidative stress, Faseb J 20,334-336.

[37] Arnesano, F., Banci, L., Bertini, I., and Bonvin, A. M. (2004) A docking approach to the study of copper trafficking proteins; interaction between metallochaperones and soluble domains of copper ATPases, Structure 12, 669-676.

[38] Achila, D., Banci, L., Bertini, I., Bunce, J., Ciofi-Baffoni, S., and Huffman, D. L. (2006) Structure of human Wilson protein domains 5 and 6 and their interplay with domain 4 and the copper chaperone HAH1 in copper uptake, Proc Natl Acad Sci U S A 103, 57295734.

[39] Comstra, H. S., McArthy, J., Rudin-Rush, S., Hartwig, C., Gokhale, A., Zlatic, S. A., Blackburn, J. B., Werner, E., Petris, M., D'Souza, P., Panuwet, P., Barr, D. B., Lupashin, V., Vrailas-Mortimer, A., and Faundez, V. (2017) The interactome of the copper transporter ATP7A belongs to a network of neurodevelopmental and neurodegeneration factors, Elife 6.

[40] Blockhuys, S., Celauro, E., Hildesjo, C., Feizi, A., Stal, O., Fierro-Gonzalez, J. C., and Wittung-Stafshede, P. (2017) Defining the human copper proteome and analysis of its expression variation in cancers, Metallomics 9, 112-123.

[41] Gaither, L. A., and Eide, D. J. (2001) Eukaryotic zinc transporters and their regulation, Biometals 14, 251-270.

[42] Hara, T., Takeda, T. A., Takagishi, T., Fukue, K., Kambe, T., and Fukada, T. (2017) Physiological roles of zinc transporters: molecular and genetic importance in zinc homeostasis, J Physiol Sci 67, 283-301.

[43] Kambe, T., Tsuji, T., Hashimoto, A., and Itsumura, N. (2015) The Physiological, Biochemical, and Molecular Roles of Zinc Transporters in Zinc Homeostasis and Metabolism, Physiol Rev 95, 749-784.

[44] Lichten, L. A., and Cousins, R. J. (2009) Mammalian zinc transporters: nutritional and physiologic regulation, Annu Rev Nutr 29, 153-176.

[45] Kambe, T. (2013) Regulation of zinc transport, Encyclopedia of Inorganic and Bioinorganic Chemistry. Culotta V, Scott RA (eds). John Wiley \& Sons, 301-309.

[46] Ohana, E., Hoch, E., Keasar, C., Kambe, T., Yifrach, O., Hershfinkel, M., and Sekler, I. (2009) Identification of the $\mathrm{Zn} 2+$ binding site and mode of operation of a mammalian Zn2+ transporter, J Biol Chem 284, 17677-17686.

[47] Golan, Y., Alhadeff, R., Warshel, A., and Assaraf, Y. G. (2019) ZnT2 is an electroneutral proton-coupled vesicular antiporter displaying an apparent stoichiometry of two protons per zinc ion, PLoS Comput Biol 15, e1006882.

[48] Kambe, T. (2012) Molecular Architecture and Function of ZnT Transporters, Curr Top Membr 69, 199-220. 
[49] Paroutis, P., Touret, N., and Grinstein, S. (2004) The pH of the secretory pathway: measurement, determinants, and regulation, Physiology (Bethesda) 19, 207-215.

[50] Maret, W., and Li, Y. (2009) Coordination dynamics of zinc in proteins, Chem Rev 109, 4682-4707.

[51] Costello, L. C., Fenselau, C. C., and Franklin, R. B. (2011) Evidence for operation of the direct zinc ligand exchange mechanism for trafficking, transport, and reactivity of zinc in mammalian cells, J Inorg Biochem 105, 589-599.

[52] Radhakrishnan, R., Walter, L. J., Hruza, A., Reichert, P., Trotta, P. P., Nagabhushan, T. L., and Walter, M. R. (1996) Zinc mediated dimer of human interferon-alpha $2 b$ revealed by X-ray crystallography, Structure 4, 1453-1463.

[53] Hopfner, K. P., Craig, L., Moncalian, G., Zinkel, R. A., Usui, T., Owen, B. A., Karcher, A., Henderson, B., Bodmer, J. L., McMurray, C. T., Carney, J. P., Petrini, J. H., and Tainer, J. A. (2002) The Rad50 zinc-hook is a structure joining Mre11 complexes in DNA recombination and repair, Nature 418, 562-566.

[54] Song, W. J., Sontz, P. A., Ambroggio, X. I., and Tezcan, F. A. (2014) Metals in proteinprotein interfaces, Annu Rev Biophys 43, 409-431.

[55] Takeda, T. A., Miyazaki, S., Kobayashi, M., Nishino, K., Goto, T., Matsunaga, M., Ooi, M., Shirakawa, H., Tani, F., Kawamura, T., Komai, M., and Kambe, T. (2018) Zinc deficiency causes delayed ATP clearance and adenosine generation in rats and cell culture models, Commun Biol 1, 113.

[56] Suzuki, T., Ishihara, K., Migaki, H., Nagao, M., Yamaguchi-Iwai, Y., and Kambe, T. (2005) Two different zinc transport complexes of cation diffusion facilitator proteins localized in the secretory pathway operate to activate alkaline phosphatases in vertebrate cells, $J$ Biol Chem 280, 30956-30962.

[57] Fukunaka, A., Suzuki, T., Kurokawa, Y., Yamazaki, T., Fujiwara, N., Ishihara, K., Migaki, H., Okumura, K., Masuda, S., Yamaguchi-Iwai, Y., Nagao, M., and Kambe, T. (2009) Demonstration and characterization of the heterodimerization of ZnT5 and ZnT6 in the early secretory pathway, J Biol Chem 284, 30798-30806.

[58] Lasry, I., Golan, Y., Berman, B., Amram, N., Glaser, F., and Assaraf, Y. G. (2014) In situ dimerization of multiple wild type and mutant zinc transporters in live cells using bimolecular fluorescence complementation, J Biol Chem 289, 7275-7292.

[59] Suzuki, T., Ishihara, K., Migaki, H., Matsuura, W., Kohda, A., Okumura, K., Nagao, M., Yamaguchi-Iwai, Y., and Kambe, T. (2005) Zinc transporters, ZnT5 and ZnT7, are required for the activation of alkaline phosphatases, zinc-requiring enzymes that are glycosylphosphatidylinositol-anchored to the cytoplasmic membrane, J Biol Chem 280, 637-643.

[60] Fukunaka, A., Kurokawa, Y., Teranishi, F., Sekler, I., Oda, K., Ackland, M. L., Faundez, V., Hiromura, M., Masuda, S., Nagao, M., Enomoto, S., and Kambe, T. (2011) Tissue Nonspecific Alkaline Phosphatase Is Activated via a Two-step Mechanism by Zinc Transport Complexes in the Early Secretory Pathway, J Biol Chem 286, 16363-16373.

[61] Tsuji, T., Kurokawa, Y., Chiche, J., Pouyssegur, J., Sato, H., Fukuzawa, H., Nagao, M., and Kambe, T. (2017) Dissecting the Process of Activation of Cancer-promoting Zincrequiring Ectoenzymes by Zinc Metalation Mediated by ZNT Transporters, J Biol Chem 292, 2159-2173.

[62] McCormick, N. H., and Kelleher, S. L. (2012) ZnT4 provides zinc to zinc-dependent proteins in the trans-Golgi network critical for cell function and Zn export in mammary 
epithelial cells, Am J Physiol Cell Physiol 303, C291-297.

[63] Ishihara, K., Yamazaki, T., Ishida, Y., Suzuki, T., Oda, K., Nagao, M., Yamaguchi-Iwai, Y., and Kambe, T. (2006) Zinc transport complexes contribute to the homeostatic maintenance of secretory pathway function in vertebrate cells, J Biol Chem 281, 1774317750 .

[64] Kambe, T. (2011) An overview of a wide range of functions of ZnT and Zip zinc transporters in the secretory pathway, Biosci Biotechnol Biochem 75, 1036-1043.

[65] Fujimoto, S., Tsuji, T., Fujiwara, T., Takeda, T. A., Merriman, C., Fukunaka, A., Nishito, Y., Fu, D., Hoch, E., Sekler, I., Fukue, K., Miyamae, Y., Masuda, S., Nagao, M., and Kambe, T. (2016) The PP-motif in luminal loop 2 of ZnT transporters plays a pivotal role in TNAP activation, Biochem J 473, 2611-2621.

[66] Saito, Y., Ihara, Y., Leach, M. R., Cohen-Doyle, M. F., and Williams, D. B. (1999) Calreticulin functions in vitro as a molecular chaperone for both glycosylated and nonglycosylated proteins, Embo J 18, 6718-6729.

[67] Watanabe, S., Amagai, Y., Sannino, S., Tempio, T., Anelli, T., Harayama, M., Masui, S., Sorrentino, I., Yamada, M., Sitia, R., and Inaba, K. (2019) Zinc regulates ERp44dependent protein quality control in the early secretory pathway, Nat Commun 10, 603.

[68] Ellis, C. D., Wang, F., MacDiarmid, C. W., Clark, S., Lyons, T., and Eide, D. J. (2004) Zinc and the Msc2 zinc transporter protein are required for endoplasmic reticulum function, $J$ Cell Biol 166, 325-335.

[69] Reich, R., Hoffman, A., Veerendhar, A., Maresca, A., Innocenti, A., Supuran, C. T., and Breuer, E. (2012) Carbamoylphosphonates control tumor cell proliferation and dissemination by simultaneously inhibiting carbonic anhydrase IX and matrix metalloproteinase-2. Toward nontoxic chemotherapy targeting tumor microenvironment, J Med Chem 55, 7875-7882.

[70] Reich, R., Hoffman, A., Suresh, R. R., Shai, O., Frant, J., Maresca, A., Supuran, C. T., and Breuer, E. (2015) Carbamoylphosphonates inhibit autotaxin and metastasis formation in vivo, J Enzyme Inhib Med Chem 30, 767-772.

[71] Chabosseau, P., Woodier, J., Cheung, R., and Rutter, G. A. (2018) Sensors for measuring subcellular zinc pools, Metallomics 10, 229-239.

[72] Huang, Z., and Lippard, S. J. (2012) Illuminating mobile zinc with fluorescence from cuvettes to live cells and tissues, Methods Enzymol 505, 445-468.

[73] Que, E. L., Bleher, R., Duncan, F. E., Kong, B. Y., Gleber, S. C., Vogt, S., Chen, S., Garwin, S. A., Bayer, A. R., Dravid, V. P., Woodruff, T. K., and O'Halloran, T. V . (2015) Quantitative mapping of zinc fluxes in the mammalian egg reveals the origin of fertilization-induced zinc sparks, Nat Chem 7, 130-139.

[74] Fujimoto, S., Itsumura, N., Tsuji, T., Anan, Y., Tsuji, N., Ogra, Y., Kimura, T., Miyamae, Y., Masuda, S., Nagao, M., and Kambe, T. (2013) Cooperative Functions of ZnT1, Metallothionein and ZnT4 in the Cytoplasm Are Required for Full Activation of TNAP in the Early Secretory Pathway, PLoS One 8, e77445. 